\section{(A) OPEN ACCESS}

\title{
Association of diabetes and tuberculosis: impact on treatment and post-treatment outcomes
}

\author{
María Eugenia Jiménez-Corona ${ }_{1}{ }^{1}$ Luis Pablo Cruz-Hervert, ${ }^{2}$ Lourdes García-García, ${ }^{2}$ \\ Leticia Ferreyra-Reyes, ${ }^{2}$ Guadalupe Delgado-Sánchez, ${ }^{2}$ Miriam Bobadilla-del-Valle, ${ }^{3}$ \\ Sergio Canizales-Quintero, ${ }^{2}$ Elizabeth Ferreira-Guerrero, ${ }^{2}$ Renata Báez-Saldaña, ${ }^{2}$ \\ Norma Téllez-Vázquez, ${ }^{2}$ Rogelio Montero-Campos, ${ }^{2}$ Norma Mongua-Rodriguez, ${ }^{2}$ \\ Rosa Areli Martínez-Gamboa, ${ }^{3}$ José Sifuentes-Osornio, ${ }^{3}$ Alfredo Ponce-de-León ${ }^{3}$
}

\begin{abstract}
- Additional material is published online only. To view please visit the journal online (http://dx.doi.org/10.1136/ thoraxjnl-2012-201756).

${ }^{1}$ Laboratorios de Biológicos y Reactivos de México (BIRMEX) Ciudad de México, Distrito Federal México, México ${ }^{2}$ Instituto Nacional de Salud Pública, Cuernavaca, Morelos, México

${ }^{3}$ Instituto Nacional de Ciencias Médicas y de Nutrición Salvador Zubirán (INCMNSZ) Vasco de Quiroga 15, Ciudad de México, Distrito Federal México, México
\end{abstract}

\section{Correspondence to} Dr Lourdes García-García, Instituto Nacional de Salud Pública, Av. Universidad \# 655, Col. Sta. María Ahuacatitlán, Cuernavaca, Morelos C.P. 62100, México; garcigarml@gmail.com

Received 29 February 2012 Revised 15 October 2012 Accepted 24 November 2012 Published Online First 18 December 2012

\section{SLinked}

- http://dx.doi.org/10.1136/ thoraxjnl-2012-202976

To cite: JiménezCorona ME, Cruz-Hervert LP, García-García L, et al. Thorax 2013;68:214-220.

\section{ABSTRACT}

Objective To determine the clinical consequences of pulmonary tuberculosis (TB) among patients with diabetes mellitus (DM).

Methods We conducted a prospective study of patients with TB in Southern Mexico. From 1995 to 2010, patients with acid-fast bacilli or Mycobacterium tuberculosis in sputum samples underwent epidemiological, clinical and microbiological evaluation. Annual follow-ups were performed to ascertain treatment outcome, recurrence, relapse and reinfection. Results The prevalence of DM among 1262 patients with pulmonary TB was $29.63 \%(n=374)$. Patients with DM and pulmonary TB had more severe clinical manifestations (cavities of any size on the chest x-ray, adjusted $\mathrm{OR}$ (aOR) 1.80, 95\% Cl 1.35 to 2.41), delayed sputum conversion (aOR 1.51, 95\% Cl 1.09 to 2.10), a higher probability of treatment failure (aOR 2.93, 95\% Cl 1.18 to 7.23 ), recurrence (adjusted HR (aHR) 1.76, $95 \% \mathrm{Cl} 1.11$ to 2.79 ) and relapse (aHR $1.83,95 \% \mathrm{Cl}$ 1.04 to 3.23). Most of the second episodes among patients with DM were caused by bacteria with the same genotype but, in 5/26 instances (19.23\%), reinfection with a different strain occurred.

Conclusions Given the growing epidemic of DM worldwide, it is necessary to add DM prevention and control strategies to TB control programmes and vice versa and to evaluate their effectiveness. The concurrence of both diseases potentially carries a risk of global spreading, with serious implications for TB control and the achievement of the United Nations Millennium Development Goals.

\section{INTRODUCTION}

The WHO has identified diabetes mellitus (DM) as a global epidemic, mostly affecting low- and middle-income countries where $80 \%$ of all deaths from DM occur. ${ }^{1}$ Simultaneously, tuberculosis (TB) continues to be a major cause of death worldwide despite the fact that the epidemic appears to be on the verge of a decline. ${ }^{2}$ Many studies have explored the relationship between DM and TB, including a recent systematic review which showed that the risk of TB among people with DM is three times higher than in people without DM. ${ }^{3}$ Recently, WHO and the International Union Against $\mathrm{TB}$ and Lung Disease (Union) have acknowledged the need for international guidelines on the joint management and control of TB and DM and have published a

\section{Key messages}

What is the key question?

- What are the treatment and post-treatment outcomes in patients with pulmonary tuberculosis (TB) and diabetes mellitus (DM) in a high DM/TB setting?

What is the bottom line?

- Although data indicate that patients with TB and DM are probably more likely to experience negative outcomes, unsolved questions remain due to methodological limitations of previous studies. Furthermore, the frequency of relapses and reinfections is unknown.

\section{Why read on?}

- We document that patients with TB/DM have more severe treatment and post-treatment outcomes. Using molecular tools, we demonstrated that subsequent episodes among patients with DM are more likely to be due to the same bacteria as the previous episode. However, the occurrence of exogenous reinfection in one-fifth of the cases merits further consideration.

provisional collaborative framework for the care and control of both diseases. ${ }^{4}$

In this study we address some of the knowledge gaps and research needs that have recently been identified on the association between these two diseases. ${ }^{5} 6$ Since 1995 we have been conducting a population-based prospective study of pulmonary TB in Southern Mexico where almost one-third of TB patients have been previously diagnosed with DM. ${ }^{7}$ The main objective of this study was to describe the clinical manifestations and treatment and post-treatment outcomes in patients with $\mathrm{DM}$ and bacteriologically confirmed pulmonary $\mathrm{TB}$ compared with TB patients without this diagnosis.

\section{METHODS}

Study population and enrolment

We conducted a prospective study of patients with TB. Briefly, the study area includes 12 
municipalities in the Orizaba Health Jurisdiction in Veracruz State, Mexico with an extent of $618.11 \mathrm{~km}^{2}$ and 413223 inhabitants, $26.3 \%$ of whom live in rural communities. ${ }^{8}$

Between March 1995 and April 2010 we performed passive case finding supported by community health workers and screened persons aged $>15$ years who reported coughing for $>15$ days. Consenting patients with acid-fast bacilli or Mycobacterium tuberculosis in sputum samples were consecutively recruited over the 15 years and underwent epidemiological, clinical (standardised questionnaire, physical examination, chest radiography and HIV test), microbiological and molecular evaluations. We performed cultures on smearpositive sputum samples from 1995 to 2000, on all sputum samples (both smear-positive and smear-negative) from 2000 to 2005 , and on sputum samples from all previously treated TB patients as well as any new patients with TB considered at high risk of having drug-resistant TB from 2005 to 2010. Patients were considered to have DM if they had received a previous diagnosis from a physician or oral hypoglycaemic medication or insulin administration or treatment. Chest x-rays were assessed independently by certified radiologists. Staff classifying study outcomes were not blinded while laboratory personnel and radiologists were blinded to patients' DM status. Personnel were trained in the administration of standardised questionnaires that included previously validated questions. Community health workers ascertained the 'homelessness' of participants.

Following the guidelines of Mexico's National TB Control Program, between 1995 and 1998 new cases received 2 months of isoniazid $(\mathrm{H})$, rifampin $(\mathrm{R})$ pyrazinamide $(\mathrm{Z})$ plus 4 months of HR (2HRZ/4HR) and retreatment cases also received either ethambutol (E) or streptomycin (S). After 1998 the local health jurisdiction adopted the WHO standard regimen of initiating therapy with four drugs (2HRZE/4HR) for newly diagnosed patients and five drugs (2HRZES/1HRZE/5HRE) for previously treated patients. After 2000, patients harbouring isolates resistant to both isoniazid and rifampin were treated with the support of the Green Light Committee with a second-line standardised regime using at least four drugs highly likely to be effective for 18-24 months after culture conversion.

We used the operational definitions of the programme for treatment outcomes except that defaulting and death were defined according to international definitions (table 1). ${ }^{9} 10$
After treatment was completed, patients were visited annually and standardised questionnaires, smears and M tuberculosis cultures were undertaken to investigate recurrences, relapses, ${ }^{10}$ IS6110 based-reinfections and death due to $\mathrm{TB},{ }^{11}$ as defined in table 1 .

\section{HIV testing}

Voluntary HIV testing and counselling was offered to all participants. The results were given to the patient and he/she was referred to receive appropriate treatment. Testing for HIV was done using two different tests. All positive results were confirmed by western blot analysis. ${ }^{12}$

\section{Measurement of glucose concentration}

In 1166 of the 1262 patients (92.39\%) in whom a serum sample obtained after the diagnosis of TB was available, glucose determination was performed using a Synchron CX5 Delta analyser (Beckman Coulter). Glucose levels $\geq 126 \mathrm{mg} / \mathrm{dl}$ in fasting samples or $\geq 200 \mathrm{mg} / \mathrm{dl}$ for random samples were considered diagnostic. $^{13}$

\section{Mycobacteriology and genotyping}

Sputum samples were processed for $M$ tuberculosis following standardised procedures. ${ }^{14}$ Isolates were genotyped and compared using IS6110-based restriction fragment length polymorphisms (RFLP) and spoligotyping if the IS6110 RFLP patterns of the isolate had $<6$ bands. ${ }^{15}$ Patients were considered 'clustered' if $\geq 2$ isolates from different patients were identified within 12 months of each other and had $\geq 6$ IS6110 bands in an identical pattern, or $<6$ bands with identical IS6110 RFLP patterns and a spoligotype with the same spacer oligonucleotides. Cases with a unique genotype pattern (different from all other fingerprints obtained from isolates in the study population) and the first case diagnosed in each cluster probably arose from the reactivation of latent infection caused by $M$ tuberculosis strains acquired at a different time or place. ${ }^{16}$

\section{Statistical analysis}

Bivariate and multivariate analyses were used to test for differences in sociodemographic, behavioural and clinical characteristics between patients with and without DM. Rural residence and homelessness were defined as in the Population and

\section{Table 1 Definition of treatment outcomes}

Outcomes at the end of treatment

Failure

Cure

Treatment completion

Death during treatment

Default

Transfer out

Outcomes after treatment was completed

Recurrence

Relapse

Reinfections

Deaths after TB treatment was completed
Death due to TB Deaths we therapy
AFB microscopies or cultures positive at 5 months or later during treatment

Treatment completed with disappearance of signs and symptoms and $\geq 2$ AFB smears or cultures with negative results at the end of

Completion of treatment without meeting the criteria to be classified as a cure or failure

Death due to any cause during treatment

Interruption of treatment for $\geq 2$ consecutive months

Patient transferred to another institution outside the study region

A second or subsequent episode of TB confirmed by AFB smear or culture in a patient with a history of prior treatment

TB disease confirmed by AFB smear or culture that occurred after a patient was considered to have completed treatment or to have been cured. Relapse patients are included within recurrent TB

Subsequent TB episodes (recurrences and relapses) with the same genotype: $\geq 6$ IS6110 bands in an identical pattern or $<6$ bands with identical IS6110 RFLP patterns and a spoligotype with the same spacer oligonucleotides

Deaths were attributed to TB based on two of the following: death certificate with TB as the main cause of death; interview with a close caregiver who identified TB as a probable cause of death; or positive AFB smear or culture at the time of death

AFB, acid-fast bacilli; RFLP, restriction fragment length polymorphisms; $T B$, tuberculosis. 
Household Census. ${ }^{8}$ Usage of alcohol (>10 drinks per week), smoking ( $>10$ cigarettes per week), usage of illegal drugs, (marijuana, cocaine and its derivatives, heroin, methamphetamines, hallucinogens, inhalants and other drugs) were defined as in the National Survey of Addictions. ${ }^{17}$

Drug susceptibilities and genotype patterns of $M$ tuberculosis isolates from patients with and without DM were compared. To evaluate healthcare access we assessed the distance to the nearest health centre and the time elapsed between the onset of symptoms and the beginning of treatment. Fingerprints obtained from first and second or subsequent episodes were compared among recurring and relapsing patients.

In patients with pulmonary $\mathrm{TB}$, associations between $\mathrm{DM}$ and the severity of disease (as indicated by cavities of any size on chest $x$-rays), delayed sputum conversion (after $\geq 60$ days) and treatment failure were investigated by multivariate unconditional logistic regression. Variables with $\mathrm{p} \leq 0.20$ in the bivariate analysis and biological plausibility were included in multivariate models. We estimated the OR and 95\% CIs and identified the covariates that were independently associated with each outcome. We estimated adjusted HRs and 95\% CI using Cox proportional hazards models to assess the association of DM with recurrence and relapse. In these models, the outcome was the time to diagnosis of recurrence or relapse from treatment completion of the previous episode in years. The proportional hazards assumption was verified by introducing terms for the interaction between time and covariates into the model. Since serum glucose determination was available for 1166 patients (92.32\%) after the diagnosis of $\mathrm{TB}$, we reanalysed the data adding the 26 patients $(6.5 \%)$ who were unaware of their diagnosis of DM until after their diagnosis of TB. Kaplan-Meier curves were used to assess survivorship among patients with and without DM and a log-rank test was used to detect significant differences. All data analysis was performed using Stata V.10.0.

\section{RESULTS}

\section{Characteristics of patients with TB according to DM}

During the 15-year study period we recruited 1262 patients with pulmonary TB. Of these, 29.63\% (374/1262) were diagnosed with DM prior to TB diagnosis. A comparison of patients with and without DM is shown in table 2. Patients with DM were more likely to be female, older and from a higher socioeconomic level (as indicated by household characteristics), with greater access to Social Security and more years of formal education. Illegal drug and alcohol usage, homelessness and HIV infection were more frequent among subjects without DM. Retreated DM patients were more likely to harbour isolates with joint resistance to isoniazid and rifampin. Patients with DM were more likely to have TB reactivation as indicated by unique IS6110 fingerprints.

Clinical evaluation showed that patients with DM had more severe clinical manifestations (ie, higher frequency of cavities on chest $\mathrm{x}$-rays). This observation was confirmed when the association between previous DM diagnosis and cavities on chest

Table 2 Characteristics of patients with pulmonary TB (Orizaba, Veracruz, Mexico, 1995-2010)

\begin{tabular}{|c|c|c|c|c|}
\hline Characteristic & $\begin{array}{l}\text { Total number of TB } \\
\text { patients } \\
\text { n/total }(\%)\end{array}$ & $\begin{array}{l}\text { TB patients with DM } \\
\text { n/total }(\%)\end{array}$ & $\begin{array}{l}\text { TB patients without DM } \\
\text { n/total }(\%)\end{array}$ & $\begin{array}{l}\text { p } \\
\text { Value* }\end{array}$ \\
\hline Female & $532 / 1262(42.16)$ & 180/374 (48.13) & $352 / 888(39.64)$ & 0.005 \\
\hline Mean (SD) age (years) & $45.32(18.18)$ & $53.51(12.81)$ & 41.9 (18.99) & $<0.001 \dagger$ \\
\hline$>6$ years of formal schooling & $846 / 1260(67.14)$ & $271 / 373(72.65)$ & $575 / 887(64.83)$ & 0.007 \\
\hline Household with earthen floor & $267 / 1184(22.55)$ & $45 / 350(12.86)$ & $222 / 834(26.62)$ & $<0.001$ \\
\hline Rural residence & $148 / 1232(12.01)$ & $31 / 366(8.47)$ & $117 / 866(13.51)$ & 0.013 \\
\hline Median (IQR) distance to nearest health centre (metres) & 705.15 (424.19-1555.22) & $725.5(426.98-1025.30)$ & $696.91(422.40-1084.94)$ & $0.774 \ddagger$ \\
\hline Access to Social Security & $451 / 1262(35.74)$ & $184 / 374(49.20)$ & $267 / 888(30.07)$ & $<0.001$ \\
\hline$>10$ drinks per week & $282 / 1259(22.40)$ & $60 / 372(16.13)$ & $222 / 887(25.03)$ & 0.001 \\
\hline$>10$ cigarettes per week & $106 / 1259(8.42)$ & $28 / 373(7.51)$ & $78 / 886(8.80)$ & 0.449 \\
\hline Use of illegal drugs & $64 / 1261(5.08)$ & $6 / 373(1.61)$ & $58 / 888(6.53)$ & $<0.001$ \\
\hline Homelessness or residing in shelters & $46 / 1257(3.66)$ & $4 / 374(1.07)$ & $42 / 883(4.76)$ & 0.001 \\
\hline HIV infection & $24 / 1228(2.00)$ & 2/362 (0.55) & $22 / 866(2.54)$ & 0.022 \\
\hline Previous TB treatment & $153 / 1261$ (12.13) & $51 / 373(13.67)$ & $102 / 888$ (11.49) & 0.278 \\
\hline$>10$ bacilli per oil immersion field & $300 / 1262(23.77)$ & $77 / 374(20.59)$ & $223 / 888(25.11)$ & 0.085 \\
\hline Resistance to any drug§ & $190 / 919$ (20.67) & $72 / 315(22.86)$ & $118 / 604(19.54)$ & 0.238 \\
\hline Joint resistance to isoniazid and rifampin & $43 / 919(4.68)$ & $17 / 315(5.40)$ & $26 / 604(4.30)$ & 0.457 \\
\hline Joint resistance to isoniazid and rifampin in new cases & $17 / 796(2.14)$ & $4 / 275(1.45)$ & $13 / 521(2.5)$ & 0.334 \\
\hline Joint resistance to isoniazid and rifampin in retreated cases & $26 / 122(21.31)$ & $13 / 39(33.33)$ & $13 / 83(15.66)$ & 0.026 \\
\hline Unique fingerprint & $721 / 1013(71.17)$ & 238/312 (76.28) & $483 / 701(68.90)$ & 0.017 \\
\hline Fever & $905 / 1259(71.88)$ & $276 / 374(73.80)$ & $629 / 885(71.07)$ & 0.326 \\
\hline Haemoptysis & $423 / 1257$ (33.65) & $143 / 370(38.65)$ & 280/887 (31.57) & 0.015 \\
\hline Mean (SD) BMI & $21.47(4.20)$ & $23.14(4.15)$ & $20.76(4.02)$ & $<0.001 \dagger$ \\
\hline Cavities on chest $\mathrm{x}$-ray & 407/1071 (38.00) & $142 / 313(45.37)$ & 265/758 (34.96) & 0.001 \\
\hline $\begin{array}{l}\text { Median (IQR) time elapsed between onset of symptoms and } \\
\text { treatment (days) }\end{array}$ & $104.00(63.00-185.00)$ & $100.00(63.00-185.00)$ & $108(62.00-185.00)$ & $0.784 \ddagger$ \\
\hline \multicolumn{5}{|c|}{$\begin{array}{l}\text { * } \chi^{2} \text { test. } \\
\text { † Student t test. } \\
\text { ¥Mann-Whitney test. } \\
\text { §Resistance to streptomycin was found in } 6.20 \% \text { (57/919); to isoniazid in } 17.30 \%(159 / 919) ; \text { to rifampin in } 5.55 \% \text { (51/919); and to ethambutol in } 1.41 \%(13 / 919) \text { of isolates. } \\
\text { BMI, body mass index; DM, diabetes mellitus; TB, tuberculosis. }\end{array}$} \\
\hline
\end{tabular}


Table 3 Treatment outcomes among patients with pulmonary TB with and without DM (Orizaba, Veracruz, Mexico, 1995-2010)

\begin{tabular}{|c|c|c|c|c|}
\hline Outcome & $\begin{array}{l}\text { Total number of TB patients } \\
\text { n/total (\%) }\end{array}$ & $\begin{array}{l}\text { TB patients with DM } \\
\text { n/total (\%) }\end{array}$ & $\begin{array}{l}\text { TB patients without DM } \\
\text { n/total (\%) }\end{array}$ & p Value* \\
\hline \multicolumn{5}{|l|}{ Outcomes during and at the end of treatment } \\
\hline Sputum conversion after $\geq 60$ days & $350 / 873(40.10)$ & $133 / 290(45.86)$ & $217 / 583(37.22)$ & 0.014 \\
\hline Failure & $36 / 1210(2.97)$ & $17 / 363(4.68)$ & 19/847 (2.24) & 0.022 \\
\hline Cure & $864 / 1210(71.40)$ & $259 / 363(71.35)$ & $605 / 847(71.43)$ & 0.978 \\
\hline Treatment completion & $155 / 1210(12.81)$ & 49/363 (13.50) & $106 / 847(12.51)$ & 0.639 \\
\hline Death during treatment & $47 / 1210(3.88)$ & $11 / 363(3.03)$ & $36 / 847(4.25)$ & 0.314 \\
\hline Default & $95 / 1210(7.85)$ & 23/363 (6.34) & $72 / 847(8.50)$ & 0.200 \\
\hline Transfer out & $13 / 1210(1.07)$ & $4 / 363(1.10)$ & $9 / 847(1.06)$ & 0.951 \\
\hline \multicolumn{5}{|l|}{ Outcomes after treatment was completed } \\
\hline Recurrencet $\ddagger$ & $107 / 1163(9.20)$ & $41 / 352(11.65)$ & $66 / 811(8.14)$ & 0.057 \\
\hline Identical strains in first and second episodes & 55/64 (85.94) & $21 / 26(80.77)$ & 34/38 (89.47) & 0.325 \\
\hline Different strains in first and second episodes & 9/64 (14.06) & $5 / 26(19.23)$ & $4 / 38(10.53)$ & \\
\hline Relapse§, $†$ & $74 / 1019(7.26)$ & 26/308 (8.44) & $48 / 711(6.75)$ & 0.340 \\
\hline Identical strains in first and second episodes & $31 / 38(81.58)$ & 10/13 (76.92) & $21 / 25(84.00)$ & 0.593 \\
\hline Different strains in first and second episodes & $7 / 38$ (18.42) & $3 / 13(23.08)$ & $4 / 25(16.00)$ & \\
\hline \multicolumn{5}{|l|}{ Deaths after TB treatment was completed $q$} \\
\hline Death due to TB & $50 / 1198(4.17)$ & $9 / 359(2.51)$ & $41 / 839(4.89)$ & 0.059 \\
\hline Death by some cause other than TB & 203/1198 (16.94) & 104/359 (28.97) & 99/839 (11.80) & $<0.001$ \\
\hline \multicolumn{5}{|c|}{$\begin{array}{l}\text { * } \chi^{2} \text { test. } \\
\text { tWe were able to fingerprint both isolates for } 59.81 \%(64 / 107) \text { of the patients with a recurrence, including } 51.35 \%(38 / 74) \text { of the patients with a relapse. } \\
\text { †Comparison of fingerprints of first or subsequent isolates among } 19 \text { patients who recurred after default revealed matching fingerprints in } 14 \text { patients. In five patients we were unable } \\
\text { to obtain DNA on isolates of both episodes. Of the } 13 \text { patients who recurred after failure, } 9 \text { had matching fingerprints, } 2 \text { had different fingerprints and in } 2 \text { patients we were unable } \\
\text { to obtain DNA on isolates of both episodes. } \\
\text { \$Relapse patients are included within recurrent TB. } \\
\text { ISix of } 17 \text { patients who died who did not accept treatment were excluded. } \\
\text { DM, diabetes mellitus; TB, tuberculosis. }\end{array}$} \\
\hline
\end{tabular}

x-rays was tested by multivariate analysis (tables 2 and 4). We were unable to obtain chest $\mathrm{x}$-rays in 189 patients, mainly because they were unable or unwilling to attend the hospital where the studies were conducted. Online supplementary table 1 summarises the comparison between patients with and without a chest $\mathrm{x}$-ray. Characteristics such as diagnosis of DM, sex, previous TB treatment, number of bacilli per oil immersion field, drug resistance and HIV infection were similar between the two groups.

\section{Treatment outcomes}

Seventeen patients refused treatment. Of the 1056 patients who completed treatment, $761(72.06 \%)$ initiated treatment within 10 days of their diagnosis and 1039 (98.39\%) received directly

Table 4 Association of DM with selected clinical manifestations and treatment outcomes among patients with pulmonary TB by multivariate analyses

\begin{tabular}{|c|c|c|c|c|c|}
\hline Variable & $\begin{array}{l}\text { Cavities on chest } \\
\text { x-ray } \\
\text { ORt }(95 \% \mathrm{Cl}) \\
\mathrm{n}=1051\end{array}$ & $\begin{array}{l}\text { Sputum conversion } \\
\geq 60 \text { days } \\
\text { ORt }(95 \% \mathrm{Cl}) \\
n=639\end{array}$ & $\begin{array}{l}\text { Treatment failure } \\
\text { ORt }(95 \% \mathrm{Cl}) \\
\mathrm{n}=756 \ddagger\end{array}$ & $\begin{array}{l}\text { Recurrence HR§ } \\
(95 \% \mathrm{CI}) \\
n=842\end{array}$ & $\begin{array}{l}\text { Relapse HR§ }(95 \% \mathrm{CI}) \\
\mathrm{n}=731\end{array}$ \\
\hline Diabetes & $1.80(1.35 \text { to } 2.41)^{*}$ & $1.51(1.09 \text { to } 2.10)^{* * *}$ & $2.93(1.18 \text { to } 7.23)^{* * *}$ & $1.76(1.11 \text { to } 2.79)^{* * *}$ & $1.83(1.04 \text { to } 3.23)^{* * *}$ \\
\hline Men & & - & $2.9(1.02 \text { to } 8.24)^{* * *}$ & - & - \\
\hline$>10$ cigarettes per week & - & - & - & - & $2.86(1.42 \text { to } 5.75)^{* *}$ \\
\hline Previous TB treatment & - & - & $5.1(2.00 \text { to } 13.00)^{* *}$ & - & - \\
\hline $\begin{array}{l}\text { Time elapsed between onset of } \\
\text { symptoms and treatment }\end{array}$ & - & $1.01(1.01 \text { to } 1.01)^{* * *}$ & - & - & - \\
\hline$>10$ bacilli per oil immersion field & $2.11(1.57 \text { to } 2.84)^{* *}$ & - & - & - & $2.00(1.09 \text { to } 3.64)^{* * *}$ \\
\hline $\begin{array}{l}\text { Joint resistance to isoniazid } \\
\text { and rifampin }\end{array}$ & - & $5.80(1.63 \text { to } 29.71)^{* *}$ & $37.46(12.21 \text { to } 114.85)^{*}$ & $8.41(4.57 \text { to } 15.46)^{*}$ & $12.85(4.91 \text { to } 33.58)^{*}$ \\
\hline Failure or default & - & - & - & $4.83(2.79 \text { to } 8.35)^{*}$ & - \\
\hline HIV infection & $0.32(0.09$ to 1.12$) \rrbracket$ & - & - & $4.23(1.03 \text { to } 17.42)^{* * *}$ & - \\
\hline Body mass index & $0.95(0.92 \text { to } 0.98)^{* *}$ & - & - & - & - \\
\hline \multicolumn{6}{|c|}{$\begin{array}{l}{ }^{*} \mathrm{p}<0.001 ;{ }^{* *} \mathrm{p}<0.01 ;{ }^{* * *} \mathrm{p}<0.05 \text {. } \\
\text { +Unconditional logistic regression model. } \\
\text { ‡Patients who failed were compared with patients who cured or completed treatment - variable not included in the final model. } \\
\text { §Cox proportional hazards model. } \\
\text { १Not significant } \\
\text { DM, diabetes mellitus; TB, tuberculosis. }\end{array}$} \\
\hline
\end{tabular}


observed therapy. Table 3 shows the outcomes during and at the end of treatment and after treatment was completed. Bivariate and multivariate analyses controlled for sociodemographic and clinical variables showed that patients with DM had a higher probability of delayed sputum conversion and treatment failure (tables 3 and 4).

Patients were followed for an average of 61.7 months (IQR 26.6-97.4). Cox adjusted hazards ratios controlled for relevant confounding factors revealed that patients with DM had a significantly greater probability of recurrence and relapse (table 4).

There were 26 patients who were unaware of their diagnosis of DM until after their diagnosis of TB, which represent $6.50 \%$ of the 400 patients with a diagnosis of DM. Multivariate models reanalysing the association of a diagnosis of DM showed that DM continued to be associated with an increased likelihood of cavities on the chest $\mathrm{x}$-ray, sputum conversion $>60$ days, treatment failure, recurrence and relapse (see online supplementary table 2).

We were able to fingerprint both $M$ tuberculosis isolates in 64 of 107 patients $(59.81 \%)$ with a recurrence, including 38 of 74 patients $(51.35 \%)$ with a relapse. Most of the second episodes among patients with DM were caused by bacteria with the same genotype but, in 5 of 26 instances (19.23\%), reinfection with a different strain occurred (table 3 ). There was no difference in the proportion of individuals who recurred within 12 months after completion of treatment and harboured the same genotype $(26 / 55,47.27 \%)$ and individuals who were reinfected with a different genotype $(2 / 9,22.22 \%, \mathrm{p}=0.2)$.

The frequencies of death during treatment among patients with and without DM were similar according to crude analyses. After TB treatment was completed, mortality due to some other cause than TB was higher among patients with DM (table 3). Patients with DM had a lower survival rate when death from other causes was analysed (figure $1 \mathrm{~A}, \mathrm{p}<0.001$ ), while patients without DM had lower survival rates when death from TB was analysed (figure $1 \mathrm{~B}, \mathrm{p}=0.012$ ). Renal failure, alcoholic cirrhosis of the liver, cardiovascular diseases and DM were listed as the main causes of death on the death certificate in those patients whose death was attributed to a cause other than TB (table 5).

\section{DISCUSSION}

The data presented in this prospective cohort study show that patients with DM and TB have more severe clinical manifestations, delayed sputum conversion and a higher probability of treatment failure, recurrence and relapse. Using molecular tools, we found that subsequent episodes among patients with DM are due to bacteria with the same genotype or are caused by reinfection with bacteria with a different genotype. It is therefore imperative to implement the collaborative framework recommended by WHO and the Union broadly to prevent and control TB among patients with DM. ${ }^{4}$

The frequency of DM among patients with pulmonary TB observed in this study was high $(29.63 \%)$ and similar to that reported among Mexican Americans ${ }^{18}$ and in other regions. ${ }^{19} 20$

Treatment outcomes in patients with TB and DM have been a subject of debate. Although some data indicate that patients with DM are probably more likely to experience negative outcomes, the published literature suffers from limitations associated with study design, methods of diagnosing DM, outcome definitions and failure to control for important confounders. Moreover, there is a deficiency in the number of studies performed in settings with high burdens of both diseases. ${ }^{5}$
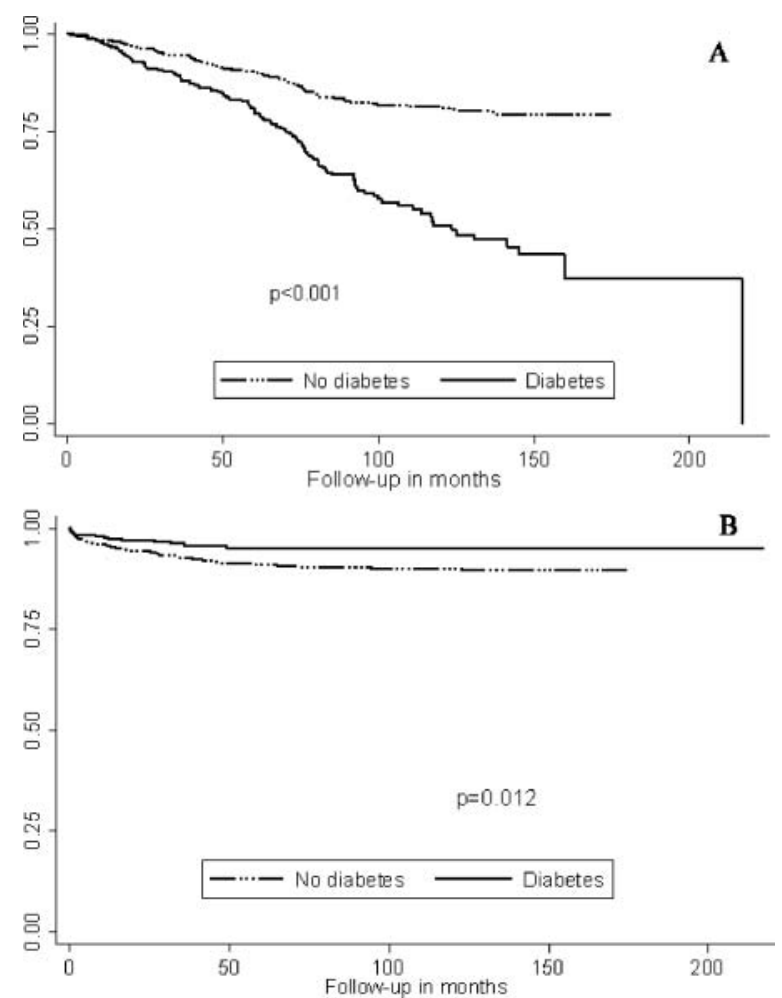

Figure 1 Kaplan-Meier survival curves by diagnosis of diabetes. (A) Death by some cause other than tuberculosis $(\mathrm{TB})(p<0.001)$ and (B) death from TB $(p=0.012)$. Estimated survival of patients with bacteriologically confirmed pulmonary TB according to the presence of diabetes; patients with diabetes had lower survival rates when death from other causes was analysed $(A, p<0.001)$ while patients without diabetes had lower survival rates when death from TB was analysed $(B, p=0.012)$.

Table 5 Causes of death on death certificate according to death attributed to tuberculosis (TB) and death attributed to other causes*

\begin{tabular}{|c|c|c|c|c|}
\hline $\begin{array}{l}\text { Causes of death } \\
\text { according to death } \\
\text { certificate }\end{array}$ & $\begin{array}{l}\text { Total } \\
\text { deaths } \\
\mathrm{N}=306\end{array}$ & $\begin{array}{l}\text { Death } \\
\text { attributed } \\
\text { to TB } \\
\mathrm{N}=89\end{array}$ & $\begin{array}{l}\text { Death } \\
\text { attributed } \\
\text { to other } \\
\text { causes } \\
\mathrm{N}=217\end{array}$ & p Value \\
\hline Tuberculosis & $79(25.81)$ & $61(68.53)$ & $18(8.29)$ & $<0.001$ \\
\hline Renal failure & $50(16.33)$ & $3(3.37)$ & $47(21.65)$ & $<0.001$ \\
\hline Alcoholic cirrhosis of liver & 37 (12.09) & $4(4.49)$ & $33(15.20)$ & 0.009 \\
\hline Cardiovascular diseases & $34(11.11)$ & $6(6.74)$ & $28(12.90)$ & 0.119 \\
\hline Diabetes mellitus & $19(6.20)$ & $1(1.12)$ & $18(8.29)$ & 0.018 \\
\hline $\begin{array}{l}\text { Chronic obstructive } \\
\text { pulmonary disease }\end{array}$ & $14(4.57)$ & $3(3.37)$ & $11(5.06)$ & 0.518 \\
\hline Pneumonia & $14(4.57)$ & $0(0.00)$ & $14(6.45)$ & 0.014 \\
\hline Malignant neoplasms & $13(4.24)$ & $2(2.24)$ & $11(5.06)$ & 0.266 \\
\hline HIVIAIDS & $10(3.26)$ & $3(3.37)$ & $7(3.22)$ & 0.948 \\
\hline Accidents & $6(1.96)$ & $0(0.00)$ & $6(2.76)$ & 0.113 \\
\hline Other causest & $31(10.13)$ & $6(6.74)$ & $25(11.52)$ & 0.208 \\
\hline
\end{tabular}

*Deaths were attributed to tuberculosis based on two of the following: death certificate with tuberculosis as the main cause of death; interview with a close caregiver who identified tuberculosis as a probable cause of death; or sputum or culture-confirmed tuberculosis at the time of death. ${ }^{11}$

tIncludes gastrointestinal diseases (5); sepsis, unspecified (5); protein-energy malnutrition (5); epilepsy (3); alcoholic liver disease (2); cerebrovascular accident (2); abscess of lung (1); hepatic failure (1); lupus erythematosus (1); and not otherwise specified (6). 
We found that clinical and radiological manifestations are more severe among patients with DM and TB, as has been previously described. ${ }^{21-23}$ Our observation regarding delayed sputum conversion at 60 days agrees with most studies, although the timing of delayed conversion has been shown to vary. ${ }^{5}$

The independent risk of failure as a sole outcome associated with DM in our study was 2.93 (95\% CI 1.18 to 7.23 ), which is higher than the previously reported pooled risk associated with the combined outcome of failure and death of 1.69 (95\% CI 1.36 to 2.12$).^{5}$ In the majority of previous studies the inability to analyse failure as the sole outcome is most likely due to small sample sizes. ${ }^{23} 24$

We also found higher independent risks of recurrence and relapse among patients with DM. In contrast to the previous literature, ${ }^{5}$ the use of $M$ tuberculosis fingerprinting allowed us to document whether patients with DM experiencing subsequent episodes had TB caused by the same bacteria as the previous episode or reinfection with a different strain. Molecular tools have provided direct evidence for the occurrence of exogenous reinfection among both immunocompetent and immunocompromised individuals, ${ }^{16}$ although patients with DM have not been specifically studied. We demonstrated that patients with DM are more likely to have infections caused by the same bacteria as the previous episode. However, the occurrence of exogenous reinfection in one-fifth of the cases merits further consideration. Exogenous TB reinfection in patients with DM might be due to nosocomial TB transmission occurring as a result of attending clinics where there is a high prevalence of diagnosed and undiagnosed TB, as has been described for HIV-infected patients. ${ }^{25}$

Based on our results, DM thus appears to have an aggravating effect on TB. Although the physiopathology of the coexistence of these two diseases has yet to be elucidated, changes to the immune system of patients with active TB and DM have been described, including reductions in the activation of alveolar macrophages and in the capacity to produce interleukin $10,{ }^{26} 27$ reductions in Th1 cytokines $^{2829}$ and alterations in the innate response. ${ }^{30}$

We documented higher rates of mortality from causes other than TB among patients with DM. We studied death during treatment and extended follow-up to investigate mortality after completion of treatment. The existing literature indicates a higher risk of death during TB treatment, particularly when adjusting for confounding factors, ${ }^{5}$ but a limitation of these studies has been ascertaining the cause of death. In this work we based the cause of death on two of three criteria as previously reported. ${ }^{11}$ Other authors have also described higher rates of overall mortality among patients with DM who had TB without determining $\mathrm{TB}$ as the cause of death. ${ }^{31}{ }^{32}$ We postulate that earlier and higher rates of non-TB-related mortality in patients with DM explain why we were unable to detect higher rates of TB-related deaths despite poor TB treatment outcomes among them.

\section{Strengths and limitations of the study}

The strengths of our study include the following: (1) recruitment of patients previously diagnosed with DM to avoid the inclusion of patients with active TB and impaired glucose tolerance that improves or returns to levels prior to TB disease after receiving effective TB treatment; (2) a large sample size; (3) survival analyses that controlled for relevant confounders, thus permitting the detection of negative outcomes including relapse and recurrence; and (4) the use of molecular tools that allowed us to compare strains between subsequent episodes in the same patient. Our approach therefore overcomes many of the limitations of previous studies that were identified in the systematic review conducted by Baker et al. ${ }^{5}$
One limitation is that, because significant socioeconomic differences were noted between patients with and without DM, it is possible that persons with better access to healthcare services were more likely to be diagnosed with both DM and TB. However, TB cases were actively recruited by community health workers and prior analyses indicated that TB is more commonly diagnosed in persons of lower socioeconomic status. ${ }^{33}$ Moreover, there were no differences between patients with and without DM with regard to indicators of health access. Thus, there was no differential opportunity for the diagnosis of TB according to the availability of health services. The study also does not reflect the long-term evolution of DM control as we did not measure metabolic control or complications. We were therefore unable to determine whether metabolic control had any impact on clinical outcomes. We may have underestimated the real frequency of DM as the prevalence of DM was based on self-reporting of diagnosis by a physician. This method has been found to be adequate for epidemiological studies, although it underestimates the real frequency of DM by approximately $20 \%$. ${ }^{34}$ We consider our data to be unbiased since, when we reanalysed data including both patients with a previous DM diagnosis and individuals who were unaware of their DM until after TB was diagnosed, observed associations continued to be statistically significant.

\section{CONCLUSIONS AND POLICY IMPLICATIONS}

Our results show that DM can exacerbate the clinical course of TB. Given the absence of international guidelines on the joint management and control of TB and DM, national programmes need to establish a coordinated response to these two diseases at both the organisational and clinical levels. ${ }^{4}$ The occurrence of exogenous reinfection in patients with subsequent episodes of TB emphasises the need to prevent transmission in high-risk environments, particularly in healthcare settings.

Given the growing epidemic of DM worldwide, it is necessary to add DM prevention and control strategies to TB control programmes and vice versa and to evaluate their effectiveness. The concurrence of both diseases potentially carries a risk of global spreading, with serious implications for TB control and the achievement of the United Nations Millennium Development Goals. $^{35}$

Acknowledgements We thank the population, patients and healthcare workers of the Orizaba Health Jurisdiction, Mexico for their generous support and cooperation. The authors wish to thank Drs Carmen Soler and Carlos Conde for performing HIV testing and Drs Manuel Tielve, Ruben Acevedo and Luis Felipe Alva for chest radiograph interpretation. The authors especially thank Dr Peter Small for his contributions in initiating this population-based cohort study.

Contributors MEJC, LPCH, LGG, JSO and APL participated in the study design, data management, data analysis and wrote the manuscript. LFR, GDS, MBV, SCQ, EFG, RBS, NTV and RAMG contributed to the study design and implementation. RCM and NMR participated in the study design and contributed to the analyses. All authors had full access to all of the data and analysis results and can take responsibility for the integrity of the data and the accuracy of the data analysis. LGG is the guarantor.

Funding This work was supported by the Mexican Secretariat of Health, the National Institutes of Health of the USA (A135969 and K01TW000001), the Wellcome Trust (176W009), the Howard Hughes Medical Institute (55000632) and the Mexican Council of Science and Technology (SALUD 2003-C01-132, SEP-2004-C01-47499/A1, FOSSIS 2005-03 (15203), FOSSIS 2005-2 14475, SALUD-2008-C01-87332, SALUD-2010-01-140178). The funding agencies did not participate in the study design; in the collection, analysis and interpretation of data; in the writing of the report; and in the decision to submit the article for publication.

\section{Competing interests None.}

Ethics approval Ethical approval was obtained from the Ethical Commission of the Instituto Nacional de Salud Pública (approval numbers CI-017, 107, 180, 211 and 275). Participants gave informed consent before taking part. All TB patients were 
referred to health facilities to receive treatment in accordance with the stipulations of the National Program for the Prevention and Control of TB and the National Program for the Prevention and Control of DM.

Provenance and peer review Not commissioned; externally peer reviewed.

Open Access This is an Open Access article distributed in accordance with the Creative Commons Attribution Non Commercial (CC BY-NC 3.0) license, which permits others to distribute, remix, adapt, build upon this work non-commercially, and license their derivative works on different terms, provided the original work is properly cited and the use is non-commercial. See: http://creativecommons.org/ licenses/by-nc/3.0/

\section{REFERENCES}

1 World Health Organization. Diabetes. Fact sheet Number 312. August 2011. http:// www.who.int/mediacentre/factsheets/fs312/en/index.html (accessed Nov 2011)

2 World Health Organization. Global tuberculosis report 2012. http://www.who.int/tb/ publications/global_report/en/index.html (accessed Oct 2011).

3 Jeon CY, Murray MB. Diabetes mellitus increases the risk of active tuberculosis: a systematic review of 13 observational studies. PLOS Med 2008;5:e152.

4 World Health Organization. Collaborative framework for care and control of tuberculosis and diabetes. http://www.who.int/diabetes/publications/ tb diabetes2011/en/index.html (accessed Nov 2011).

5 Baker MA, Harries $A D$, Jeon $C Y$, et al. The impact of diabetes on tuberculosis treatment outcomes: a systematic review. BMC Med 2011;9:81.

6 Harries $A D$, Murray $M B$, Jeon $C Y$, et al. Defining the research agenda to reduce the joint burden of disease from diabetes mellitus and tuberculosis. Trop Med Int Health 2010;15:659-63.

7 Ponce-De-Leon A, Garcia-Garcia Md Mde L, Garcia-Sancho MC, et al. Tuberculosis and diabetes in southern Mexico. Diabetes Care 2004:27:1584-90.

8 Instituto Nacional de Estadística, Geografía, e Informática (INEGI). XIII Censo General de Población y Vivienda 2010). México 2011. http://www.inegi.gob.mx (accessed May 2011).

9 Modificación a la Norma Oficial Mexicana NOM-006-SSA2-1993, para la prevención y control de la tuberculosis en la atención primaria a la salud: Secretaria de Salud, Diario Oficial de la Federación, Mexico, 2000.

10 World Health Organization, et al. Revised international definitions in tuberculosis control. Int J Tuberc Lung Dis 2001;5:213-15.

11 Garcia-Garcia Mde L, Ponce-De-Leon A, Garcia-Sancho MC, et al. Tuberculosis-related deaths within a well-functioning DOTS control program. Emerg Infect Dis 2002;8:1327-32.

12 Norma Oficial Mexicana NOM-010-SSA2-2010, Para la prevención y el control de la infección por Virus de la Inmunodeficiencia Humana. Secretaria de Salud, Diario Oficial de la Federación, Mexico, 2010.

13 American Diabetes Association. Diagnosis and classification of diabetes mellitus. Diabetes Care 2012:35(Suppl 1):S64-71.

14 Pfyffer G, Palicova F. Mycobacterium: general characteristics, laboratory detection, and staining procedures. In: Versalovic J, Carrol K, Funke G, et al. eds. Manual of Clinical Microbiology. 10th edn. Washington, D.C: ASM Press, 2011:472-502.

15 Barlow RE, Gascoyne-Binzi DM, Gillespie SH, et al. Comparison of variable number tandem repeat and IS6110-restriction fragment length polymorphism analyses for discrimination of high- and low-copy-number IS6110 Mycobacterium tuberculosis isolates. J Clin Microbiol 2001:39:2453-7.

16 Mathema B, Kurepina NE, Bifani PJ, et al. Molecular epidemiology of tuberculosis: current insights. Clin Microbiol Rev 2006;19:658-85.
17 Secretaría de Salud. Encuesta Nacional de Adicciones 2008. México 2009 http:/l www.insp.mx/encuesta-nacional-de-adicciones-2008.html (accessed May 2011).

18 Restrepo BI, Fisher-Hoch SP, Crespo JG, et al. Type 2 diabetes and tuberculosis in a dynamic bi-national border population. Epidemiol Infect 2007;135:483-91.

19 Alisjahbana B, van Crevel R, Sahiratmadja E, et al. Diabetes mellitus is strongly associated with tuberculosis in Indonesia. Int J Tuberc Lung Dis 2006; 10:696-700.

20 Singla R, Khan N, Al-Sharif N, et al. Influence of diabetes on manifestations and treatment outcome of pulmonary TB patients. Int J Tuberc Lung Dis 2006; 10:74-9.

21 Perez-Guzman C, Torres-Cruz A, Villarreal-Velarde H, et al. Atypical radiological images of pulmonary tuberculosis in 192 diabetic patients: a comparative study. Int J Tuberc Lung Dis 2001;5:455-61.

22 Tatar D, Senol G, Alptekin S, et al. Tuberculosis in diabetics: features in an endemic area. Jpn J Infect Dis 2009;62:423-7.

23 Wang CS, Yang CJ, Chen HC, et al. Impact of type 2 diabetes on manifestations and treatment outcome of pulmonary tuberculosis. Epidemiol Infect 2009;137:203-10.

24 Alisjahbana B, Sahiratmadja E, Nelwan EJ, et al. The effect of type 2 diabetes mellitus on the presentation and treatment response of pulmonary tuberculosis. Clin Infect Dis 2007:45:428-35.

25 Bock NN, Jensen PA, Miller B, et al. Tuberculosis infection control in resource-limited settings in the era of expanding HIV care and treatment. $J$ Infect Dis 2007;196(Suppl 1):S108-13.

26 Wang $\mathrm{CH}$, Yu CT, Lin HC, et al. Hypodense alveolar macrophages in patients with diabetes mellitus and active pulmonary tuberculosis. Tuberc Lung Dis 1999;79:235-42.

27 van Exel E, Gussekloo J, de Craen AJ, et al. Low production capacity of interleukin-10 associates with the metabolic syndrome and type 2 diabetes : the Leiden 85-Plus study. Diabetes 2002:51:1088-92.

28 Tsukaguchi K, Okamura H, Matsuzawa K, et al. (Longitudinal assessment of IFN-gamma production in patients with pulmonary tuberculosis complicated with diabetes mellitus). Kekkaku: (Tuberculosis) 2002;77:409-13.

29 Tsukaguchi K, Yoneda T, Yoshikawa M, et al. (Case study of interleukin-1 beta, tumor necrosis factor alpha and interleukin-6 production peripheral blood monocytes in patients with diabetes mellitus complicated by pulmonary tuberculosis). Kekkaku: (Tuberculosis) 1992;67:755-60.

30 Restrepo BI, Fisher-Hoch SP, Pino PA, et al. Tuberculosis in poorly controlled type 2 diabetes: altered cytokine expression in peripheral white blood cells. Clin Infect Dis 2008;47:634-41.

31 Santo $\mathrm{AH}$. Deaths attributed to multiple causes and involving tuberculosis in the state of Rio de Janeiro Brazil between 1999 and 2001. J Bras Pneumol 2006:32:544-52.

32 Oursler KK, Moore RD, Bishai WR, et al. Survival of patients with pulmonary tuberculosis: clinical and molecular epidemiologic factors. Clin Infect Dis 2002;34:752-9.

33 Sanchez-Perez H, Flores-Hernandez J, Jansa J, et al. Pulmonary tuberculosis and associated factors in areas of high levels of poverty in Chiapas, Mexico. Int $\mathrm{J}$ Epidemiol 2001;30:386-93.

34 Centers for Disease Control and Prevention (CDC). Self-reported prevalence of diabetes among Hispanics-United States, 1994-1997. MMWR Morb Mortal Wkly Rep 1999:48:8-12.

35 Stevenson CR, Forouhi NG, Roglic G, et al. Diabetes and tuberculosis: the impact of the diabetes epidemic on tuberculosis incidence. BMC Public Health 2007:7:234. 